\title{
Infective keratitis in soft contact lens wearers
}

\author{
R. L. COOPER AND I. J. CONSTABLE \\ From the Department of Ophthalmology, University of Western Australia, Royal Perth Hospital, Perth, \\ Western Australia
}

SUMMARY Eight cases of infective keratitis are reported in wearers of soft contact lenses. Four of them had normal eyes and were wearing lenses on a continual basis. One was wearing a lens continually for therapeutic reasons. Three others were wearing lenses daily or intermittently. The four latter cases were using contaminated lens solutions. Two of the continual lens wearers lost vision to the point of blindness. A significant factor in their bad outcome was the fact that both lived in areas remote from adequate ophthalmic services.

Serratia liquefaciens was implicated in one case. This is thought to be the only reported case of corneal abscess due to this organism in the past 16 years. S. marcescens was grown in another case from the lens solutions and carrying case.

The introduction of the soft contact lens with improved patient tolerance and ease of fitting has led to rapid increase in its use both for therapeutic and optical indications. The high oxygen transfer of the 70 and $85 \%$ water content lenses has prompted the use of constant wear in some centres. In view of the widespread use of soft contact lenses it is surprising how few reports of complications in normal eyes have accumulated in the literature. This is a report of 8 cases of infective keratitis associated with soft contact lens wear, mainly in normal eyes, with both daily intermittent and constant wear.

\section{Case summaries}

\section{Infection with constant wear soft lens for optical indications}

Case 1. A 78-year-old female from a remote town presented with a 3-day history of painful red right eye. She had worn a Sauflon $70 \%$ water content constant wear lens for unilateral right aphakia for 2 years, and visited her contact lens practitioner every 3 months 350 miles from home for lens cleaning.

On examination visual acuity was right eye 6/24 with the contact lens, 6/12 left with spectacle correction. There was a right purulent conjunctivitis with 2 central superficial corneal abscesses. Corneal scraping culture grew Pseudomonas aeruginosa. She responded well to local tetracycline and systemic carbenicillin, with minimal residual scarring and visual acuity of $6 / 18$.

Address for reprints: Department of Ophthalmology, Royal Perth Hospital, Wellington Street, Perth, Western Australia 6000
Eight months later with continued wearing of the right contact lens she presented again with the same history and vision in the right eye reduced to hand movements. At this admission there was 1 central superficial corneal abscess and a severe haemorrhagic iritis with marked fibrin exudate in the anterior chamber of the right eye. Culture from the corneal scrapings grew Serratia liquefaciens from enrichment media. She responded favourably to intensive gentamicin and steroid therapy, which left her with a corneal nebula. The contact lens was not worn again. Visual acuity in that eye recovered to $6 / 18$ with aphakic spectacle correction.

Case 2. A 29-year-old male had been wearing soft contact lenses for 5 years. No record of the type has been obtainable. For 12 months before admission wear was continuous.

He was admitted after 1 week's history of a painful red right eye. Vision was perception of light right eye and 6/36 left eye without correction. There was a large central full-thickness right corneal abscess with minimal peripheral corneal oedema (Fig. 1). No growth was obtained on culture. Very slow and incomplete healing occurred over 6 weeks on amphotericin B and gentamicin subconjunctival injections, with systemic amoxycillin, gentamicin, and Probenecid. He took his own discharge. Visual acuity 1 year later was $6 / 24$ without correction. A small central corneal scar remained.

Case 3. A 23-year-old female had been wearing an $85 \%$ Sauflon contact lens continuously for 2 years for simple myopia when she developed a painful red left eye 2 days before admission. Visual acuities were $6 / 24$ right, and hand movements left 


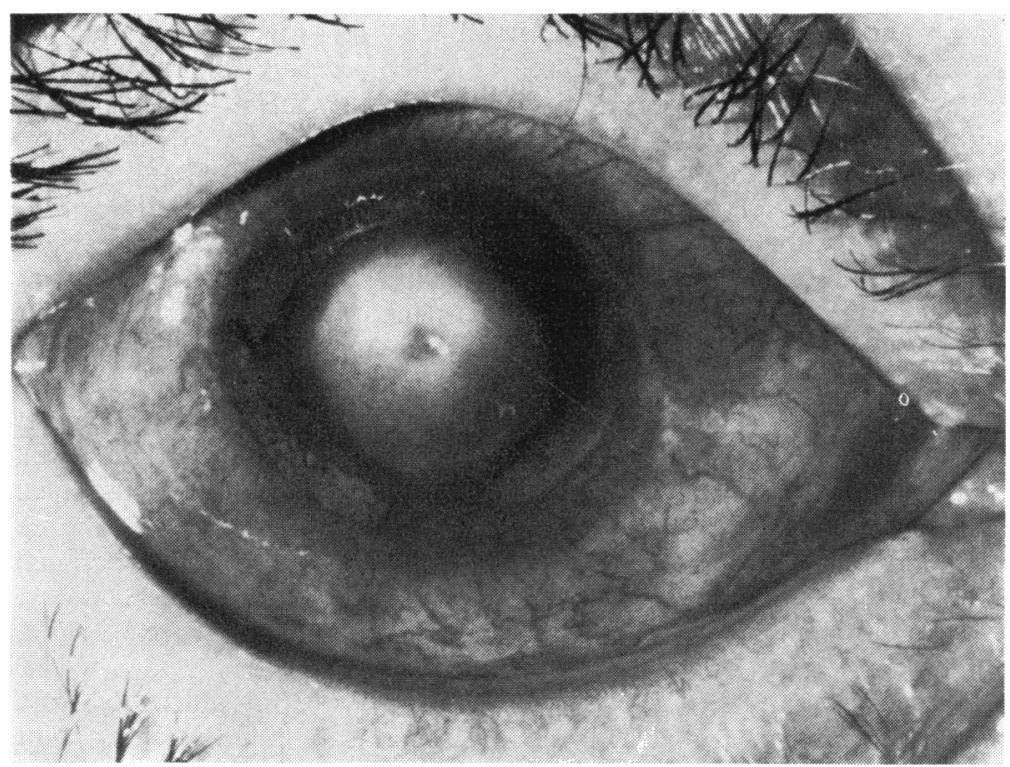

Fig. 1 Photograph of case 2. Large central full thickness corneal abscess due to continual wear of soft contact lens

without correction. Six superficial yellow/white abscesses were scattered across the centre of the left cornea (Fig. 2). They involved the epithelium and Bowman's membrane and were surrounded by considerable oedema. Several marginal yellow abscesses were also noted along the superior limbus. There was a $1 \mathrm{~mm}$ left hypopyon, with fibrin occluding the pupil. In both eyes 10 to 12 midstromal leashes of new vessels extended $2 \mathrm{~mm}$ into the corneae from the limbus. Scrapings and culture grew Staphylococcus aureus from the left eye.

Treatment with 1 subconjunctival injection of gentamicin sulphate $20 \mathrm{mg}$ was followed by continuous infusion of gentamicin sulphate $3 \mathrm{mg} / \mathrm{kg}$ per 24 hours in normal saline, delivered at a rate of approximately 1 drop every minute into the superior conjunctival fornix. The end of a thin Silastic tube, as used for canalicular intubation, was



Fig. 2 Photograph of case 3. Central superficial corneal abscesses (arrow) due to continuous wear of soft contact lenses 
placed in the upper fornix. The tubing was glued to the cheek and temple with Dow Corning silicone rubber adhesive. (Medical Grade 'Adhesive B'.) A fine butterfly needle was introduced into the distal end of the tubing and an intravenous giving set attached to the infusion bottle.

The abscesses healed in 4 days, at which time the infusion was stopped. Corrected visual acuity in the left eye was $6 / 12$ after 4 weeks. No further follow-up was possible.

Case 4. A 19-year-old female from a remote town presented with 1 week's history of a painful red eye, the onset of which was 1 day after a swim in a muddy river. She was wearing Hydron lenses constantly for myopia. For 3 days before admission she was treated with Soframycin eye drops, and systemic Tobramycin.

On admission vision right $6 / 9$, vision left hand movements. There was a large sloughing left central corneal ulcer surrounded by stromal oedema. Cultures for herpes virus, bacteria and fungi were unrewarding. No organisms were found on microscopy. Despite treatment with subconjunctival framycetin and amphotericin B and local nystatin a hypopyon developed after 5 days. This cleared rapidly over the ensuing 10 days and the ulcer healed. She was left with a dense central stromal scar and vision of $3 / 60$ in the affected eye. She continues to wear a right soft lens and has after 2 years had a successful penetrating left keratoplasty.

\section{Infection with constant lens wear for therapeutic indication}

Case 5. A 78-year-old female was prescribed a Sauflon $85 \%$ lens for treatment of bullous keratopathy (Fuchs's combined dystrophy) of the right eye. Six days after fitting the lens and shortly after pouring a cleaning solution into the eye she experienced severe burning pain. (She had been instructed to do this regularly each day by her contact lens practitioner.) On examination visual acuities were $6 / 60$ right with the lens and 6/18 left with spectacle correction. She had a purulent conjunctival discharge, moderate epithelial irregularity, and stromal oedema.

Cultures of the conjunctival discharge and the lens solution both grew Enterobacter aerogenes. She responded rapidly to local gentamicin and chloramphenicol. The eye remains irritable from her bullous keratopathy, and no change in visual acuity has occurred. Contact lens wear has not been resumed.

Infections with intermittent and daily wear for optical indications

Case 6. This 24 -year-old nurse was wearing a $70 \%$ water content Sauflon soft contact lens for about
12 to 16 hours a day for myopia (-8·00D.S.). About 4 months after starting their wear she developed a painful right eye. She removed both lenses for 4 days and then reinserted the left lens. She rapidly developed pain in the left eye. On admission vision was $6 / 6$ right eye, $6 / 60$ left eye with glasses. She was found to have a healing right paracentral corneal ulcer, and 2 small paracentral superficial left corneal ulcers with $1 \mathrm{~mm}$ left hypopyon. Culture from the left corneal ulcers yielded no organisms. However, culture of the solution used for cleaning the lens grew Pseudomonas pyocyanea and Escherichia coli. She responded well to subconjunctival injections of gentamicin, local chloramphenicol, and systemic amoxycillin. She no longer wears contact lenses and has 2 small superficial paracentral nebulae in the left cornea, and 1 paracentral right nebula. Visual acuities are 6/9 right, 6/12 left with spectacle correction.

Case 7. A 56-year-old male intermittently wore optical cosmetic Sauflon soft contact lenses. Not having worn the lenses for 4 months, he inserted the right lens directly from a 4-month-old sterilising solution without resterilising the lens. After about 4 hours he developed severe pain in the right eye.

On examination visual acuity was 6/18 right, 6/9 left with glasses. There was a $1 \mathrm{~mm}$ superficial paracentral corneal abscess, folds in Descemet's membrane, and marked flare and cells in the anterior chamber. Gram film of the corneal scrapings showed Gram-negative rods, which proved to be Escherichia coli on culture. The contact lens solution grew Enterobacter aerogenes and Pseudomonas species.

Response to treatment, initially with amphotericin $B$ and specifically with gentamicin locally, was rapid. The central abscess healed, leaving a small residual subepithelial nebula, and 6/9 vision, corrected, in that eye.

Case 8. A 19-year-old female had been wearing Hydron soft contact lenses occasionally for 3 months when she developed a painful red left eye. She had inserted the lens in the eye after a break in wear of 2 weeks without again rendering the lens aseptic, and had wet the lens with Normal saline before insertion. Visual acuity was 6/12 right, 6/36 left, without correction. An area of fine punctate epithelial keratitis was visible in the upper half of the left cornea, with minimal fluorescein staining. There were fine keratic precipitates and a faint flare. Cultures grew Staphylococcus albus from the conjunctiva and Serratia marcescens from both contact lens solutions and the carrying case. She responded well to removal of the lens and local chloramphenicol drops. After 1 month she resumed wearing the soft contact lens. Final visual acuity in the affected eye was 6/9. 
Table 1 Infective keratitis associated with continuous wear of soft contact lenses

\begin{tabular}{|c|c|c|c|c|c|c|c|}
\hline Case no. & Age & $\operatorname{Sex}$ & Indication & Lens type & Duration of wear & Organism & Final acuity \\
\hline $1 a$ & 78 & $\mathbf{F}$ & Unilateral aphakia & Saufion $70 \%$ & 2 years & $\begin{array}{c}\text { Pseudomonas } \\
\text { aeruginosa }\end{array}$ & $\begin{array}{l}6 / 12 \\
\text { With contact lens }\end{array}$ \\
\hline $1 b$ & 78 & $\mathbf{F}$ & Unilateral aphakia & Sauflon $70 \%$ & 2 years 8 months & $\begin{array}{l}\text { Serratia } \\
\quad \text { liquefaciens }\end{array}$ & $\begin{array}{l}6 / 12 \\
\text { With glasses }\end{array}$ \\
\hline 2 & 29 & $\mathbf{M}$ & Optical & Not known & 1 year & $\begin{array}{l}\text { None, presumed } \\
\text { mycotic }\end{array}$ & $\begin{array}{l}6 / 60 \\
\text { at } 5 / 12 \\
\text { Dense scar }\end{array}$ \\
\hline 3 & 23 & $\mathbf{F}$ & Optical (myopia) & Sauflon $85 \%$ & 2 years & Staph. aureus & $\begin{array}{l}6 / 12 \\
\text { With glasses }\end{array}$ \\
\hline 4 & 19 & $\mathbf{F}$ & Optical (myopia) & Bausch \& Lomb & 3 months & $\begin{array}{l}\text { None, presumed } \\
\text { mycotic }\end{array}$ & $\begin{array}{l}3 / 60 \\
\text { Dense scar }\end{array}$ \\
\hline 5 & 78 & $\mathbf{F}$ & $\begin{array}{l}\text { Therapeutic bullous } \\
\text { keratopathy }\end{array}$ & Sauflon $85 \%$ & 6 days & $\begin{array}{c}\text { Enterobacter } \\
\text { aerogenes }\end{array}$ & No change \\
\hline
\end{tabular}

Five of the above cases of infective keratitis wore soft contact lenses continuously, 4 prescribed for optical and 1 for therapeutic indications (Table 1). Of the patients with normal eyes 1 was aphakic: she had no filtering blebs or loose sutures to account for her infection, and had 2 episodes of corneal abscess. Two of the patients were blind after healing, 1 of whom has had a successful penetrating keratoplasty. Both of these patients lived in remote areas and were referred late to ophthalmic services. One of them went swimming in a muddy river immediately before the infection while wearing the contact lenses. The patient wearing the therapeutic lens was using a contaminated irrigating solution.

The second group consisted of 3 patients wearing soft lenses on a daily or intermittent basis (Table 2). The cause of the keratitis in 2 of these patients was failure to render their lenses aseptic after a period of 2 or more weeks between insertions. All 3 patients had contaminated lens solutions and carrying cases.

\section{Discussion}

The literature was reviewed from 1956, from which year several reports were made of infective keratitis and even endophthalmitis occurring in hard contact lens wearers with normal eyes (Payrau and Perdriel, 1956; Heydacker, 1956; Lansche and Lee, 1960; Nauheim, 1962; Fitzgerald et al., 1962; Dixon et al., 1966). Two reports were found of infections due to trauma to filtering blebs by hard contact lenses (Wild, 1962; Ashline and Ellis, 1968). Only 2 reports were found of infective keratitis occurring in normal eyes wearing soft contact lenses on a daily or intermittent basis (Thomson, 1973; Ruben, 1976) and one in constant wear soft lenses for optical indications (Ruben, 1976).

However, several reports have been made of this complication in abnormal eyes wearing therapeutic soft lenses on a continual basis (Brown et al., 1974; Dohlman et al., 1973; Dohlman, 1974; Ruben, 1975). In 1 report of punctate epithelial keratitis in continual soft lens wearers for optical indications no infective aetiology was suggested for this complication (Brown and Lobascher, 1975). Infection in $30 \%$ of continual wear soft lenses for optical indications has been reported, but keratitis was not mentioned in this context (Benson, 1976).

Studies of the conjunctival flora of hard and soft lens wearers have shown no significant differences

Table 2 Infective keratitis associated with daily and intermittent wear of soft contact lenses

\begin{tabular}{|c|c|c|c|c|c|c|c|c|}
\hline Case no. & Age & Sex & Indication & Lens type & Wear pattern & Eye & Solutions & Final acuity \\
\hline 6 & 24 & $\mathbf{F}$ & Optical (myopia) & Sauflon $70 \%$ & $\begin{array}{l}16 \text { hours per day } \\
\text { for } 4 \text { months }\end{array}$ & None & $\begin{array}{l}\text { Pseudomonas } \\
\text { aeruginosa, } \\
\text { E. coli }\end{array}$ & $\begin{array}{l}\text { 6/9 RE } \\
6 / 12 \text { LE } \\
\text { (corrected) }\end{array}$ \\
\hline 7 & 56 & $\mathbf{M}$ & Optical & Sauflon & $\begin{array}{l}\text { Occasional for } \\
2 \text { years }\end{array}$ & E. coli & $\begin{array}{l}\text { Pseudomonas, } \\
\text { Enterobacter } \\
\text { aerogenes }\end{array}$ & $\begin{array}{l}6 / 9 \\
\text { (corrected) }\end{array}$ \\
\hline 8 & 19 & $\mathbf{F}$ & Optical & Hydron & Occasional & $\begin{array}{l}\text { Staph. } \\
\text { albus }\end{array}$ & $\begin{array}{l}\text { Serratia } \\
\quad \text { marcescens }\end{array}$ & $\begin{array}{l}6 / 9 \\
\text { With contact lens }\end{array}$ \\
\hline
\end{tabular}


from non-lens wearers until, in the case of soft lens wearers, the lenses have been worn for more than 6 months (Kapetanski et al., 1964; Winkler and Dixon, 1964; Tragakis et al., 1973).

In our series of constant wear lenses for optical indications cases 1,2 , and 3 had no predisposing factors and had worn the same lenses for more than 6 months (Table 1). Benson (1976) does not give a minimum period of time for his infected cases. The predisposing factor for infection in case 4 was a swim in a muddy river while wearing her lenses. Case 5 in the continual wear group, and each of the intermittent lens wearers reported, highlight the well-known risks of contamination of lens solutions and storage cases (Table 2). Unlike the hard lens wearers, the soft lens wearer cannot store his lenses in a dry, well-ventilated carrying case for his protection (Winkler and Dixon, 1964).

The organisms isolated in our series have all been reported previously as being contaminants of lens solutions, or normal conjunctival flora, apart from Serratia liquefaciens (case $1 b$ ) This organism caused a severe haemorrhagic iritis and a superficial corneal abscess. Serratia marcescens (case 8 ) has been implicated in causing keratoconjunctivitis, corneal abscess, or ulcer (Lazachek et al., 1971; Atlee et al., 1970; Tokunaga et al., 1969), and has recently been cultured from patients wearing soft lenses continuously and from their wetting and storage solutions (Benson, 1976). Case 3 showed signs suggestive of mycotic keratitis, and although it was not proved microbiologically there was a dramatic improvement with amphotericin B.

Predisposition to infection in contact lens wearers is thought to be due to abnormalities of the epithelium induced by poor oxygenation (Brown and Lobascher, 1975). However, evidence of abnormal metabolism like that induced by minimal trauma, including depletion of glycogen stores and ATP, has been found in animal eyes wearing contact lenses of high gas permeability (Thoft and Friend, 1975).

It is apparent that continual wear of soft contact lenses should not be prescribed in the normal eye without strict supervision. This endorses the conclusions of Brown and Lobascher (1975). Adequate instructions should be given to patients, preferably in written as well as verbal form. This should cover all types of wear pattern. Particular stress should be placed on the instructions for rendering aseptic the soft lenses and their carrying cases after an interval in wearing. Fresh solutions should be used, and carrying cases should be boilable or capable of withstanding pasteurisation. It is obvious that boiling or pasteurisation of soft contact lenses is preferable to making them aseptic by chemical means because of the dangers of solution contamination. However, the weak link in the chain always lies in the handling of lenses with contaminated fingers; hence instruction in this aspect of the lens care is just as important as in sterilisation methods. Regular cleaning of soft lenses is mandatory, especially before boiling, to prevent accretion of denatured mucus, protein, and foreign bodies.

This collection of serious infections in patients wearing soft lenses suggests that it is much commoner than published reports would imply. Control over the sterility of sterilising and cleaning solutions might need to be improved. Patients should be told to report for immediate medical examination if they develop pain or blurred vision while wearing contact lenses.

We thank the surgeons who referred cases and gave permission for publication of cases in their care.

\section{References}

Ashline, J. W., and Ellis, P. O. (1968). American Journal of Ophthalmology, 66, 960.

Atlee, W. E., Burns, R. P., and Oden. M. (1970). American Journal of Ophthalmology, 70, 31.

Benson, C. (1976). Australian Journal of Ophthalmology, 4, 99. Brown, N. A., and Lobascher, D. (1975). Proceedings of the Royal Society of Medicine, 68, 52.

Brown, S. I., Bloomfield, S., Pearce, D. B., and Tragakis, M. (1974). Archives of Ophthalmology, 91, 275.

Dixon, J. M., Young, C. A., Baldone, J. A., Halberg, G. P., Sampson, W., and Stone, W. (1966). Journal of the American Medical Association, 195, 901.

Dohlman, C. H., Boruchoff, S. A., and Mobilia, E. F. (1973). Archives of Ophthalmology, 90, 367.

Dohlman, C. H. (1974). Transactions of the American Academy of Ophthalmology and Otolaryngology, 78, op. 399.

Fitzgerald, J. R., Kapustiak, W., and McCarthy, J. L. (1962). American Journal of Ophthalmology, 54, 307.

Heydacker, C. (1956). Klinische Monatsblätter für Augenheilkunde, 133, 588.

Kapetanski, F. M., Suie, T., Gracy, A. D., and Bitonte, J. L. (1964). American Journal of Ophthalmology, 57, 255.

Lansche, R. K., and Lee, F. C. (1960). Archives of Ophthalmology, 64, 275.

Lazachek, G. W., Boyle, G. L., Schwartz, A. L., and Leopold, I. H. (1971). Archives of Ophthalmology, 86, 599.

Nauheim, J. S. (1962). American Journal of Ophthalmology, 53,678 .

Payrau, P., and Perdriel, G. (1956). Bulletin de la Société d'Ophtalmologie de Paris, 9, 852.

Ruben, M. (1975). Transactions of the Ophthalmological Societies of the United Kingdom, 95, 75.

Ruben, M. (1976). Lancet, 1, 138.

Thoft, R. A., and Friend, J. (1975). American Journal of Ophthalmology, 80, 139.

Thomson, G. (1973). Medical Journal of Australia, 1, 29.

Tokunaga, T., Fujino, T., Yamamoto, K., and Ikeda, A. (1969). Folia Ophthalmologica (Japan), $20,862$.

Tragakis, M. P., Brown, S. I., and Pearce, D. B. (1973). American Journal of Ophthalmology, 75, 496.

Wild, J. J. (1962). American Journal of Ophthalmology, 54, 847. Winkler, C. H., and Dixon, J. M. (1964). Archives of Ophthalmology, 72, 817. 